\title{
The Underground Economy and Tax Base Erosion
}

\author{
Yu-Kun Wang \\ ${ }^{1}$ Graduate Institute of Political Economy, National Cheng Kung University, Taiwan \\ Correspondence: Yu-Kun Wang, Graduate Institute of Political Economy, National Cheng Kung University, No. \\ 1. University road, Tainan City 701, Taiwan. Tel: 886-2-2748-1691. E-mail: U1897102@ncku.edu.tw
}

$\begin{array}{lc}\text { Received: February 22, } 2013 & \text { Accepted: May 18, } 2013 \quad \text { Online Published: August 1, } 2013 \\ \text { doi:10.5539/ass.v9n10p1 } & \text { URL: http://dx.doi.org/10.5539/ass.v9n10p1 }\end{array}$

\begin{abstract}
The tax evasion behaviors of above-ground and underground economic activities differ. Above-ground economy tax evasion refers to people engaging in government sanctioned production and consumer activities and circumventing the payment of taxes mandated by law. The underground economy refers to people engaging in economic activities that are not sanctioned by the government, which is also known as the "grey economy." The main objective of engaging in underground economic activity is to avoid taxation by tax agencies. To explore the relationship between taxpayers' underground economic income reporting and tax compliance rates, this study established a utility function that included both the above-ground and underground economies, and divided public goods based on their above-ground and underground economic weight. This study analyzed taxpayers' underground economic income by adopting the probability of penalization and identifying the optimal participation rate. This study also found that taxpayers' corresponding risk aversion attitudes after becoming wealthy, or experiencing increased income, was a key factor of whether increases in the tax rate generated increases in the ratio of the underground economy labor force.
\end{abstract}

Keywords: barter transaction, concealed cost, tax base erosion, tax ethics, underground economy

\section{Introduction}

In literature related to underground economic activity (Note 1) and tax base erosion, Cowell (1990) and Cremer and Gahvari (1994) asserted that illegal concealment and legal avoidance are difficult to define in practice. McLaren (1998) indicated that because government personnel and investigation funding are limited, audits cannot be conducted on all taxpayers. He contended that this causes the after-tax above-ground sale price of goods to exceed the price of goods sold on the black market, regardless of discovery of tax evasion behaviors. McLaren referred to the price of goods sold on the black market to evade taxs as the "street price." (Note 2) Using the United States as an example, Stinespring (2011) reported that the United States has an estimated annual underground tax base erosion of nearly 300 to 400 billion USD. To avoid taxes, some taxpayers even participate in barter transactions or employ illegal immigrants.

Kolm and Nielsen (2008) found that employers and employees may agree to underreport business income in exchange for employees paying less personal income tax. They also asserted that if tax organizations enhance the enforcement of audits and increase the penalties for employers or employees who evade taxes, the production costs for employers may rise, thereby increasing unemployment rates. A higher income tax rate can actually reduce the unemployment rate. Frederiksen, Graversen, and Smith (2005) reported that because income tax is required for taxpayers' above-ground income, if taxpayers' tax-evading underground economic activities [i.e., when the manufacturer does not have an operating permit authorized by the relevant government organization (tax exempt)] are discovered, they face a substantial fine. Frederiksen, Graversen, and Smith found that a higher above-ground income tax rate can prompt the above-ground labor force to shift toward the underground economy to avoid high taxes (Note 3). Ihrig and Moe (2004) used a dynamic model to analyze how the income tax rate and tax evasion fines affect the scale of the underground economy. They assumed that if taxpayers simultaneously invest labor resources into the above-ground and underground economy, government cuts in the income tax rate or increases in tax evasion fines can reduce the scale of the underground economy. Cowell and Gordon (1988) simulated government sector estimates of the amount of tax underreported by representative taxpayers and the associated fines. Assuming that the government's fiscal policy follows the fiscal balance $G=T$ model, they found that tax evaders obtained the benefit quantity $r$ from tax evasion. However, under the $\mathrm{G}=\mathrm{T}$ model, because the tax evaders avoided paying tax, the public goods provided by the government sector were 
relatively less.

What differentiates this study from general research regarding the underground economy and tax base erosion is that the model established in this study not only includes the division of representative taxpayer income into above-ground and underground economic income, but also considers taxpayers' risk taking tendencies and its effects on their tax evasion behavior to realistically divide public goods based on the above-ground and underground economies. The remainder of this paper is organized as follows: After the introduction provided in Section 1, Section 2 describes the basic model, sequentially explores the relationship between representative taxpayers' underground economic income reporting coefficient and tax compliance rate, and calculates the optimal participation rate $\theta^{*}$ of the representative taxpayers' underground economy income. Section 3 analyzes the relationship between the key factors that boost the underground economy labor supply following an increase in the tax rate and representative taxpayers' risk aversion attitudes after experiencing changes in their wealth. The final section provides the conclusion.

\section{Establishing the Underground Economy Model}

Regarding the effects that underground economic activity has on tax base erosion, this study referenced the Cobb-Douglas household sector pattern utility function model employed by Feige and McGee (1983) (Note 4). Using this model, this study set the utility of representative taxpayers as consumption and leisure, and future consumption and leisure as the discounted time preference rate. Output was set as Y, the amount of labor as L, the quantity of capital as $\mathrm{K}$, government public investments as $\mathrm{G}_{\mathrm{I}}$, and the progress of production technology as $\chi$. The equation was written as $L=L_{0} \times e^{r t}, Y=f(K, L, G, \chi)$ and then modified into the utility function pattern shown below.

$$
\begin{aligned}
& V\left(y_{u}, y_{n}\right)=\ln y_{n}{ }^{1-\mu} \times y_{u}^{\mu} \\
& \text { s.t } y_{n}+(1-m) y_{u}=E
\end{aligned}
$$

In Eq. (1), $y_{n}$ is the representative taxpayers' observable above-ground output, $y_{u}$ is the representative taxpayers' concealed underground output, $\mu$ is the representative taxpayers' underground income coefficient value, $1-\mu$ is the representative taxpayers' above-ground income coefficient value, and $0 \leq \mu \leq 1$, $\sigma=1-\mu<1$ represents the decline in the marginal tax rate as $y_{n}$ increases (See Appendix 1). In addition, there are no guarantees that the representative taxpayers will not avoid paying taxes on their above-ground income. For example, taxpayers can underreport their salary or spread the interest on their income into different income reporting periods (years) to circumvent taxes. $E$ represents taxpayers' combined above-ground and underground income budget constraints. The above-ground income $\left(y_{n}\right)$ price is $P_{n}=1$. Because no taxes are paid on underground income $y_{u}$, this study set the underground income $\left(y_{u}\right)$ price as $P_{u}=(1-m)$. After integrating the underground income $y_{u}$, the optimal income reporting rate $\theta^{*}$ of the representative taxpayers can be calculated as shown below. This study first obtained the first-order processing conditions of Eq. (1) as follows:

$$
\begin{gathered}
L=\ln {y_{n}}^{1-\mu} \times y_{u}^{\mu}+\lambda \times\left(E-y_{n}-(1-m) y_{u}\right) \\
\frac{\partial L}{\partial y_{n}}=\frac{(1-\mu)}{y_{n}}=\lambda \\
y_{n}=\frac{(1-\mu)}{\lambda} \\
\frac{\partial L}{\partial y_{u}}=\frac{\mu}{y_{u}}=\lambda \times(1-m) \\
y_{u}=\frac{\mu}{\lambda \times(1-m)} \\
\frac{\partial L}{\partial \lambda}=E=y_{n}+(1-m) \times y_{u}
\end{gathered}
$$

Equation (2) shows that with an increase in $\mu$, the above-ground income of representative taxpayers declines. As the shadow price value $\lambda$ increases, the above-ground income of representative taxpayers again declines. Equation (3) shows that with an increase in $\mu$, the underground income of representative taxpayers increases. The higher the shadow price value $\lambda$, the lower the representative taxpayers' underground income. Equation (3) also indicates that as the above-ground income tax rate $m$ increases, taxpayers' underground income exhibits an increasing trend. This implies that increases in above-ground income tax rates cause the original above-ground income of representative taxpayers to increase because of tax circumvention and the conversion of above-ground income into underground income. Equations (2) and (3) show that when both underground and above-ground income exist simultaneously, the optimal above-ground income tax rate $m^{*}$ for representative taxpayers can be expressed as Eq. (4). 


$$
m^{*}=1-\frac{y_{n} \times \mu}{(1-\mu) \times y_{u}}
$$

Equation (4) can also be rewritten as $y_{u}=\frac{y_{n} \times \mu}{(1-m) \times(1-\mu)}$

By totaling the above-ground and underground income, this study obtained the following:

$$
\begin{gathered}
\frac{y_{n}}{y_{n}+y_{u}}=\frac{(1-m) \times(1-\mu)}{[(1+m \times(\mu-1)]}=\theta \\
\frac{y_{u}}{y_{n}+y_{u}}=1-\theta \\
\frac{y_{u}}{y_{n}}=\frac{1-\theta}{\theta}=v
\end{gathered}
$$

Equation (5a) shows the reported ratio $\theta$ of above-ground income of the representative taxpayers to their total income, which is inversely proportional to the representative taxpayers' underground income coefficient value $\mu$. When the above-ground income tax rate $m$ increased, the percentage of the representative taxpayers' above-ground income in the total ratio of reported income $\theta$ declined. Equations (5b) and (5c) show that the higher the $v$, the more severe the representative taxpayers' tax base erosion.

Because Eq.(5a), the above-ground income coefficient of the representative taxpayers should be set as

$1-\mu=\beta>0$, then (5a) can be rewritten as $\theta=\frac{(1-m) \times \beta}{1-\beta \times m}$

$$
\begin{aligned}
& \text { When } \beta \neq 1 \text {; then } \beta-\theta=\left(\frac{\beta \times m \times(1-\beta)}{(1-\beta \times m)}\right)>0 \\
& \text { When } \beta=1 \text {; then } \beta-\theta=\left(\frac{\beta \times m \times(1-\beta)}{(1-\beta \times m)}\right)=0
\end{aligned}
$$

Because $1 \geq \beta$, Eq. (6) shows that $\beta \geq \theta$. This means that the representative taxpayers' above-ground income reporting coefficient $\beta \geq$ their tax compliance rate $\theta$. With the known values of $1-\mu=\beta$ and the above-ground income tax rate $m$, Eq. (6) can be used to calculate the tax compliance rate $\theta$; an example is provided below.

If $\beta=0.8$ and $m=0.8$, the tax compliance rate $\theta$ is $\theta=\frac{(1-m) \times \beta}{1-\beta \times m}=0.44$

$\beta=0.8$ and $m=0.3$, the tax compliance rate $\theta$ is $\theta=\frac{(1-m) \times \beta}{1-\beta \times m}=0.73$

The above examples indicate that when $\beta$ is equal, the higher the $m$, the lower the $\theta$. (Note 5) Further calculating Eq. (6), this study obtained the following

$$
\frac{\partial \theta}{\partial \beta}=\frac{(1-m)}{(1-\beta \times m)}+\frac{(1-m) \times m \times \beta}{(1-\beta \times m)^{2}}>0
$$

Analysis of the relationship between the changing Eq.(7) (Note 6) parameter and representative taxpayers' above-ground total income reporting rate $\theta$ was conducted as follows:

1) When $\beta=1, \theta=1, \mu=0, v=\frac{1-\theta}{\theta}=0$

This indicates that when $V\left(y_{u}, y_{n}\right)=\ln y_{n}$, the value of underground income is 0 , and all the representative taxpayers have above-ground income.

2) When $\beta=0, \theta=0, \mu=1, v=\frac{1-\theta}{\theta}=\frac{1}{0}$

This indicates that when $V\left(y_{u}, y_{n}\right)=\ln y_{u}$, the value of above-ground income is 0 , and all the representative taxpayers' income has been converted into underground income. This is the worst tax base erosion situation.

3) When $1>\beta>0,0<\theta<1,0<\mu<1$, then $v=\frac{1-\theta}{\theta}>0$.

The first-order condition process was conducted using Eq. (6)

$$
\frac{\partial \theta}{\partial m}=\frac{(\beta-1) \times \beta}{(1-\beta \times m)^{2}}<0
$$

Equation (7a) shows that when $1>\beta>0$, an increase in the above-ground income tax rate reduces the tax compliance rate $\theta$. This indicates that the representative taxpayers' tax evasion behaviors increased. 
Based on Eq. (5a) $\frac{(1-m) \times(1-\mu)}{[(1+m \times(\mu-1)]}=\theta$, this study further explored the following scenarios:

1) When $m=1$

$$
\theta=\frac{(1-m) \times \beta}{1-\beta \times m}=0
$$

This indicates that in this situation, the tax compliance rate is $\theta=0$, the lowest possible value.

2) When $m=0$ (Note 7)

$$
\theta=\frac{(1-m) \times \beta}{1-\beta \times m}=\beta
$$

In this situation, the tax compliance rate is $\theta>0$ and equal to the representative taxpayers' above-ground income coefficient value $\beta$.

Proposition 1: Assuming that $0<m<1$ and $0<\theta<1$, a decline in the above-ground income tax rate causes representative taxpayers to consider their tax compliance rate $\theta$, then the premise of an increase in the effective tax rate $r_{e}$ is $\beta<\frac{2 m-1}{m^{2}}$.

Inference 1: Based on Eq. (5a), $\theta=\frac{(1-m) \times \beta}{1-\beta \times m}$. Assuming the tax compliance rate is $\frac{y_{n}}{y_{n}+y_{u}}$ and $r_{e}$ is the effective tax rate after the tax compliance rate $\theta$ is considered, then $r_{e}=m \times \theta$. According to Eq. (7a), when $m \downarrow$, it causes $\theta \uparrow$, which leads to $r_{e} \uparrow$ or $r_{e} \downarrow$. However, this outcome is subject to the following prerequisite condition (Note 8):

$$
\frac{\partial r_{e}}{\partial m}=\frac{\beta\left(1-2 m+\beta \times m^{2}\right)}{(1-\beta \times m)^{2}}
$$

Equation (8) shows that as the above-ground income tax rate reduced the effective tax rate after the considered tax compliance rate increased. The prerequisite for $\frac{\partial r_{e}}{\partial m}<0$ is $\beta<\frac{2 m-1}{m^{2}}$. That is, when $\beta<\frac{2 m-1}{m^{2}}$, the above-ground income tax rate $m$ decreased because representative taxpayers' tax compliance rate $\theta$ increased, thereby increasing the effective tax rate $r_{e}$. This finding assumes that regardless of whether the tax evasion behaviors of representative taxpayers are discovered, the concealed cost is 0 . If $H\left(s^{*}\right)=\int_{0}^{\infty}(h(s) d s)=0$ and $H\left(s^{*}\right)=\int_{0}^{\infty}(h(s) d s)>0$, then Eq. (2) can be revised as $L=\ln \left(y_{n}\right)^{1-\mu} \times y_{u}^{\mu}+\lambda \times\left(E-y_{n}-(1-m) y_{u}+\int_{0}^{\infty}(h(s) d s)\right)$. Simultaneously, Eq. (3) can be revised as $\frac{\partial L}{\partial \lambda}=E=y_{n}+(\boldsymbol{I}-m) y_{u}-\int_{0}^{\infty}(h(s) d s)$. This does not alter the results derived from Eq. (4) to (8). Considering that the concealed cost paid by taxpayers exceeds 0 , the prerequisite of increases in the effective tax rate integrated with the tax compliance rate must still satisfy $\beta<\frac{2 m-1}{m^{2}}$.

\subsection{Concealed Costs and Underground Economic Income}

To investigate how concealed costs affect representative taxpayers' underground income level, this study further investigated how representative taxpayers' unreported income and concealed costs affected the results of Eqs. (4) to (8). Referencing relevant definitions of concealed cost parameters established by Chen (2003) (Note 9), this study revised the expression of concealed cost as (Note 10) $H\left(s^{*}\right)=h_{0}(e)^{2}+h_{1}(1-\theta)^{2}$. Of which, $h_{0}(e)^{2}$ is the above-ground income concealed cost rate of representative taxpayers, and $e$ is the unreported ratio of the representative taxpayers' above-ground income $y_{n}$, assuming that $h_{0}>0, \frac{\partial h_{0}(e)^{2}}{\partial e}=2 h_{0} \times e$. Similarly, the $h_{1}(1-\theta)^{2}$ on the right side of the equation is the concealed cost ratio of the representative taxpayers' underground income, which is $h_{1}>0.1-\theta=\frac{y_{u}}{y_{n}+y_{u}}$ is the ratio of the representative taxpayers' underground income to overall income. The higher the $(1-\theta)$, the higher the underground income concealment costs $h_{1}$. The $h_{l}$ in this case exhibits a secondary titration correlation; that is, $\frac{\partial h_{1}(1-\theta)^{2}}{\partial \theta}=-2 h_{1} \times(1-\theta)$. When the concealed cost parameter is substituted into Eq. (1), the following can be obtained

$$
\begin{aligned}
L= & \ln \left(\left(1-h_{0}(e)^{2}\right) \times y_{n}\right)^{1-\mu} \times\left(\left(1-h_{1}(1-\theta)^{2}\right) \times y_{u}\right)^{\mu} \\
& +\lambda \times\left(E-\left(1-h_{0}(e)^{2}\right) \times y_{n}-\left(1-m-h_{1}(1-\theta)^{2}\right) \times y_{u}\right)
\end{aligned}
$$


Under income budget constraints, the first-order condition process included in the above equation (Lagrangian expression) to obtain the $y_{n}$ of the representative taxpayers is as follows:

$$
\begin{gathered}
\frac{\partial L}{\partial y_{n}}=\frac{(1-\mu)}{y_{n}}-\lambda \times\left(1-h_{0}(e)^{2}\right)=0 \\
y_{n}=\frac{(1-\mu)}{\lambda \times\left(1-h_{0}(e)^{2}\right)}
\end{gathered}
$$

Further analysis show that

$$
\frac{\partial y_{n}}{\partial h_{0}}=\frac{(1-\mu)}{\lambda} \times\left(1-h_{0}(e)^{2}\right)^{-2} \times\left(2 h_{0}(e)\right)>0
$$

Equation (9a) shows that the higher the representative taxpayers' above-ground income concealment cost $h_{0}(e)^{2}$, the higher the representative taxpayers' above-ground income $y_{n}$. This implies that the higher the tax evasion costs, the lower the representative taxpayers' incentives to evade taxes. Similarly, the optimal first-order processing conditions for $y_{u}$ are as follows:

$$
\begin{gathered}
\frac{\partial L}{\partial y_{u}}=\frac{\mu}{y_{u}}-\lambda \times\left(1-m-h_{1}(1-\theta)^{2}\right)=0 \\
y_{u}=\frac{\mu}{\lambda \times\left(1-m-h_{1}(1-\theta)^{2}\right)}
\end{gathered}
$$

Further analysis shows that

$$
\frac{\partial y_{u}}{\partial \theta}=\frac{-\mu}{\lambda} \times\left(1-m-h_{1}(1-\theta)^{2}\right)^{-2} \times\left(2 h_{1} \times(1-\theta)\right)<0
$$

Based on Eq. (5a), $\theta=\frac{y_{n}}{y_{n}+y_{u}}$. Equation (9c) shows that assuming the total income $\sum Y=y_{n}+y_{u}$ does not change in the short-term, an increase in $\theta$ reduces the underground income $y_{u}$ of representative taxpayers. In other words, $\theta \uparrow \Rightarrow y_{u} \downarrow \Rightarrow y_{n} \uparrow$. Further analysis of how changes in the above-ground income tax rate $m$ affects the underground income $y_{u}$ of representative taxpayers was conducted as follows:

$$
\frac{\partial y_{u}}{\partial m}=\frac{\mu}{\lambda} \times\left(1-m-h_{1}(1-\theta)^{2}\right)^{-2}>0
$$

Equation (9d) is the underground income change multiplier caused by changes in the above-ground income tax rate. According to Eq. (9d), regardless of whether the costs of concealing representative taxpayers' underground income are considered, increases in the above-ground income tax rate increase the underground income of representative taxpayers.

Proposition 2: When $-\left.\frac{\partial y_{n}}{\partial y_{u}}\right|_{U=\text { cons tan } t}=\frac{M U_{y u}}{M U_{y n}}$, the optimal above-ground income equilibrium tax rate when both above-ground and underground income exist is:

$$
m^{*}=1-h_{1}(1-\theta)^{2}-\frac{y_{n} \times \mu \times\left(1-h_{0}(e)^{2}\right)}{(1-\mu) \times y_{u}}
$$

Inference 2: Based on Eq. (9d), when the total income $\Sigma Y=y_{n}+y_{u}$ does not change in the short-term, the higher the above-ground income tax rate $m$, the higher the $y_{u}$. This indicates that as the above-ground income tax rate increases, the incentive for representative taxpayers to evade above-ground income tax also increases, increasing their underground income $y_{u}$.

In addition, when $\frac{\partial L}{\partial \lambda}=E-\left(1-h_{0}(e)^{2}\right) y_{n}+\left(1-m-h_{1}(1-\theta)^{2}\right) y_{u}=0$, Eqs. (9) and (9b) show the following: (a) that both underground and above-ground income exists; (b) representative taxpayers' unreported income is related to the concealed cost; and (c) the marginal utility of above-ground income $=$ the marginal utility conditions of underground income. In other words, under equal $-\left.\frac{\partial y_{n}}{\partial y_{u}}\right|_{U=\text { cons tan } t}=\frac{M U_{y u}}{M U_{y n}}$ conditions (Note 11), the optimal above-ground income equilibrium tax rate $m^{*}$ under stable conditions can be obtained as shown in Eq. (9e):

$$
m^{*}=1-h_{1}(1-\theta)^{2}-\frac{y_{n} \times \mu \times\left(1-h_{0}(e)^{2}\right)}{(1-\mu) \times y_{u}}
$$

\subsection{Adding the Effects that Public Goods Have on Underground Economic Income}

Public goods exist in a practical economic society. The study temporarily discounted consumer public goods and whether an equal allocation of productive public goods exists in the underground and above-ground economy, 
and added productive public goods into the tax model to explore its effect on representative taxpayers' underground income and utility. Assuming that the population in an economic society has a fixed short-term growth rate of $\frac{\dot{N}}{N}=0$, and all representative taxpayers have the same characteristics, then the representative taxpayers' intertemporal instantaneous utility function can be expressed as follows:

$$
\underset{c(t)}{\operatorname{Max}} U=\int_{t=0}^{\infty} e^{-\rho t} \times \frac{c_{t}^{1-\sigma}}{1-\sigma} d t
$$

Equation (10) is the total discount rate of the fixed relative risk aversion utility function. The instantaneous consumption is $c(t), \sigma>0$ is the reciprocal of the elasticity of intertemporal substitution (EIS), and $\rho>0$ is the representative taxpayers' time preference rate. $\sum Y=y_{n}+y_{u}$ assumes that the representative taxpayers invest capital $K$ into both above-ground and underground production sectors. This differs significantly from general underground economy models because underground economic laborers (e.g., such as illegal workers or immigrants) worry about receiving a fine or having to pay taxes, or even being deported, if discovered by the government. This causes underground laborers to avoid using productive public goods as above-ground economic laborers. Therefore, this economic taxes model establishes the difference between the productive public goods provided by the government for above-ground and underground economic sectors. In this study, the above-ground production sectors' public goods are denoted as $G_{p}$ (Note 12). Practically, the $G_{p}$ received by the underground production sector should be less than the $G_{p}$ received by the above-ground sectors. This study also set $\mathrm{b}$ as the ratio of production-type public goods received by underground economic sectors to the quantity of productive-type public goods received by the above-ground economic sector $(0<b<1)$. When excessive numbers of taxpayers use productive-type public goods for production, congestion effects similar to club goods can result. This reduces the amount of productive-type public goods that can be employed by each representative taxpayer. If 1-s is the ratio of labor capital invested by representative taxpayers ( $\mathrm{k}$ units) into the above-ground economic sector for production, $\mathrm{s}$ is the ratio of labor capital invested into the underground economic sector for production, $\psi(N)$ is the number of representative taxpayers who use public goods in the economic society, A is the production technology $(\mathrm{A}>0), y=F(N, K)$ is the representative taxpayers' original production function, and $k$ represents the labor capital per sector in $\mathrm{k}=\mathrm{K} / \mathrm{N}$, then the production function can be changed to $y=N \times f(k)$.

If $F_{k}>0$ and $F_{k k}<0$, and assuming Inada conditions were established, then $\lim _{K \rightarrow 0} F_{K}=\lim _{N \rightarrow 0} F_{N}=\infty$ and $\lim _{K \rightarrow \infty} F_{K}=\lim _{N \rightarrow \infty} F_{N}=0$. (Note 13) Referencing Barro (1990) regarding the $A K$ production function pattern, (Note 14) this study revised and obtained the representative taxpayers' above-ground and underground income production functions, as shown in Eqs. (11) and (11a).

1) Representative taxpayers' above-ground income

$$
y_{n}=A \times\left(\frac{G_{p}}{\psi(N)}\right)^{\alpha} \times(1-s) \times k
$$

Representative taxpayers' underground income

$$
y_{u}=A \times\left(\frac{b \times G p}{\psi(N)}\right)^{\alpha} \times s \times k
$$

Therefore, the representative taxpayers' above-ground post-tax production income can be expressed as

$$
\begin{aligned}
y_{n}^{A}= & \left(1-q_{n}\right) \times\left[(1-(1-e) \times m)+\left(1-q_{n}-\tau \times q_{n}\right) \times m \times e-h_{o}(e)^{2}\right] \times y_{n}+ \\
& q_{n} \times\left[(1-(1-e) \times m)-\tau \times e \times m-h_{o}(e)^{2}\right] \times y_{n} \\
= & {\left[1-m \times\left(1-2 \times e+2 \times e \times q_{n}+2 \times e \times q_{n} \times \tau-q_{n}^{2} \times e-q_{n}^{2} \times e \times \tau\right)-h_{o}(e)^{2}\right] \times y_{n} } \\
= & \left(1-m_{E}\right) \times y_{n}
\end{aligned}
$$

where $m_{E}=m \times\left(1-2 \times e+2 \times e \times q_{n}+2 \times e \times q_{n} \times \tau-q_{n}^{2} \times e-q_{n}^{2} \times e \times \tau\right)-h_{o}(e)^{2}$,

$m_{E}$ represents the government's effective tax rate for above-ground income, $\tau$ is the penalty rate, $\left(1-q_{n}\right)$ is the probability of the above-ground income not being exposed, $q_{n}$ is the probability of the above-ground income being exposed, $e$ is the unreported ratio of the representative taxpayers' above-ground economy, $h_{o}(e)^{2}$ is the concealed cost of the representative taxpayers' above-ground income $\left(h_{o}(e)^{2}>0\right)$, and $e$ is the multiplier of $h_{0}$. Similarly, the representative taxpayers' underground production income can be expressed as 


$$
\begin{aligned}
y_{u}^{A}= & \left(1-q_{u}\right) \times\left[1+\left(1-q_{u}-\tau \times q_{u}\right) \times m-h_{1}(1-\theta)^{2}\right] \times y_{u}+ \\
& q_{u} \times\left[(1-\tau \times m)-h_{1}(1-\theta)^{2}\right] \times y_{u} \\
= & {\left[1-m \times\left(2 \times q_{u}+2 \times q_{u} \times \tau-q_{u}^{2} \times \tau-q_{u}^{2}-1\right)-h_{1}(1-\theta)^{2}\right] \times y_{u} } \\
= & \left(1-m_{F}\right) \times y_{u}
\end{aligned}
$$

In Eq. (11c), $m_{F}=m \times\left(2 \times q_{u}+2 \times q_{u} \times \tau-q_{u}^{2} \times \tau-q_{u}^{2}-1\right)+h_{1}(1-\theta)^{2}$, which denotes the government's effective tax rate of underground income. In Eq. (11c), $h_{1}(1-\theta)^{2}$ is the concealed cost of the representative taxpayers' underground income.

According to $h_{1}^{\prime}>0,1-\theta=\frac{y_{u}}{y_{n}+y_{u}}$. By substituting $y_{n}=A \times\left(\frac{G_{p}}{\psi(N)}\right)^{\alpha} \times(1-s) \times k$ into Eq. (11) and the $y_{u}=A \times\left(\frac{b \times G_{p}}{\psi(N)}\right)^{\alpha} \times s \times k$ of (11a) into Eqs. (11b) and (11c), this study obtained Eqs. (11d) and (11e) as follows:

$$
\begin{gathered}
y_{n}^{A}=\left(1-m_{E}\right) \times A \times\left(\frac{G_{p}}{\psi(N)}\right)^{\alpha} \times(1-s) \times k \\
y_{u}^{A}=\left(1-m_{F}\right) \times \mathrm{A} \times\left(\frac{\mathrm{b} \times \mathrm{G}_{\mathrm{p}}}{\psi(N)}\right)^{\alpha} \times s \times k
\end{gathered}
$$

From the government's fiscal balance perspective, the government's tax revenue and fines for representative taxpayers' above-ground and underground income equals the government subsidy $g_{i c}$, which is the average cost that the government incurs to audit each taxpayer's above-ground and underground income for tax evasion. This can be expressed as Eq. (12):

$$
m \times\left[(1-e)+\tau \times q_{n} \times e\right] \times y_{n}+y_{u} \times m \times \tau \times q_{u}=\frac{\phi_{u} \times H\left(\ell_{u}\right) \times q_{u} \times y_{u}}{\Omega\left(N_{1}\right)}+\frac{\phi_{n} \times H\left(\ell_{n}\right) \times q_{n} \times y_{n}}{\Omega\left(N_{2}\right)}+g_{i c}
$$

$H\left(\ell_{t}\right)$ in Eq. (12) represents the government's technical manpower when investigating tax evasion, and $\phi$ is the marginal cost per unit of technical manpower. When $\phi>0, \Omega\left(N_{1}\right)$ and $\Omega\left(N_{2}\right)$ separately represent the manpower invested by the government into investigating above-ground and underground income tax evasion. When the government's investigation costs are positively correlated with representative taxpayers' probability of discovery $\left(q_{n}\right.$ and $\left.q_{u}\right), g_{i c}$ represents the government subsidy that each person can receive.

This study assumes that less public goods are allocated to earning underground economic income compared to that for earning above-ground economic income. If $y_{u}=A \times\left(\frac{b \times G p}{\psi(N)}\right)^{\alpha} \times s \times k$ in Eq. (11a), then $0<b<1$. According to Eq.(5b), $\frac{y_{u}}{y_{n}+y_{u}}=1-\theta$. If $b=1-\theta$, the public goods allocated to representative taxpayers' underground economic income is less than that allocated to their above-ground economic income. If $\mathrm{b}$ and $\frac{y_{u}}{y_{u}+y_{n}}$ exhibit a fixed ratio (Note 15), by conducting first-order processing of the capital goods in the above-ground economic sector in Eq. (11d) and the underground economic sector in Eq. (11e), the following can be obtained:

$$
\begin{gathered}
\frac{\partial y_{n}^{A}}{\partial k}=\left(1-m_{E}\right) \times A \times\left(\frac{G_{p}}{\psi(N)}\right)^{\alpha} \times(1-s) \\
\frac{\partial y_{u}^{A}}{\partial k}=\left(1-m_{F}\right) \times \mathrm{A} \times\left(\frac{\mathrm{b} \times \mathrm{G}_{\mathrm{p}}}{\psi(N)}\right)^{\alpha} \times \mathrm{s}
\end{gathered}
$$

In a situation where the above-ground and underground economic sectors' capital investment rate of return is equal, then Eq. (13) equals (13a). By substituting $1-\theta=b$ into Eq. (13a), the $\theta$ in Eq. (13b) and the $1-\theta$ in Eq. (13c) can be obtained. (Note 16)

$$
\begin{gathered}
\theta=1-\left[\frac{\left(1-m_{\mathrm{E}}\right) \times(1-s)}{\left(1-m_{\mathrm{F}}\right) \times s}\right]^{\frac{1}{\alpha}}=\frac{y_{\mathrm{n}}}{y_{\mathrm{u}}+y_{n}} \\
1-\theta=\left[\frac{\left(1-m_{\mathrm{E}}\right) \times(1-s)}{\left(1-m_{\mathrm{F}}\right) \times s}\right]^{\frac{1}{\alpha}}=\frac{y_{\mathrm{u}}}{y_{\mathrm{u}}+y_{n}}
\end{gathered}
$$

When public goods are included, and assuming that the depreciation in capital investment $\delta$ is not zero, the change in representative taxpayers' above-ground income capital accumulation can be obtained using Eq. (13d). 


$$
\begin{aligned}
\dot{k}_{n} & =\left(1-m_{E}\right) \times y_{n}-c=\left(1-m_{E}\right) \times A \times\left(\frac{G_{p}}{\psi(N)}\right)^{\alpha} \times(1-s) \times(1-\delta) \times k-c \\
& =\left(r_{n}^{k}-\delta\right) \times k \times(1-s)-c
\end{aligned}
$$

The $\mathrm{c}$ in Eq. (13d) is the representative taxpayers' consumption level, and the $r_{n}^{k}$ is the representative taxpayers' above-ground post-tax capital rate of return. (Note 17) Similarly, the change in representative taxpayers' underground capital accumulation can be expressed as Eq. (13e).

$$
\begin{aligned}
\dot{k_{u}} & =\left(1-m_{F}\right) \times y_{u}-c=\left(1-m_{F}\right) \times A \times\left(\frac{G_{p} \times b}{\psi(N)}\right)^{\alpha} \times s \times(1-\delta) \times k-c \\
& =\left(r_{u}^{k}-\delta\right) \times k \times s-c
\end{aligned}
$$

In Eq. (13e), $r_{u}^{k}$ is the representative taxpayers' underground post-tax capital rate of return. Because the effective tax rate of underground income in Eq. (11c) is $m_{F}=m \times\left(2 \times q_{u}+2 \times q_{u} \times \tau-q_{u}^{2} \times \tau-q_{u}^{2}-1\right)+h_{1}(1-\theta)^{2}>0$ (Note 18), if the government wishes to reduce the underground economic sectors' capital accumulation, it can attempt to achieve $r_{u}^{k}-\delta<0$. This means that the post-tax capital rate of return of the market's capital investment in underground economic sector is less than the capital depreciation rate $\delta$. (Note 19)

\subsection{The Effects that the Income Tax Rate Has on Above-Ground and Underground Economic Consumption}

Except for Propositions 1 and 2 mentioned previously, this study further established a closed economic system, where numerous representative taxpayers of the same characteristics exist. Each representative taxpayer pursues the goal of lifelong utility maximization. When the depreciation in capital goods $\delta$ is not zero, the representative taxpayers' above-ground income utility is (Note 20)

$$
\int_{0}^{\infty} u\left(C_{t}, G_{t}\right) \exp (-\rho t) d t
$$

Assuming that consumer public goods $G_{c}=0$, then $G_{p}$ and the tax rate $\mathrm{m}$ are exogenous. The Hamiltonian optimal control function shows the utility function pattern as follows:

$$
\begin{aligned}
H= & \frac{c^{1-\sigma}-1}{1-\sigma} \times e^{-\rho t}+\lambda \times e^{-\rho t} \times\left[\left(1-m_{E}\right) \times A \times\left(\frac{G_{p}}{\psi(N)}\right)^{\alpha} \times(1-s) \times k-\delta \times k \times(1-s)-c\right] \\
= & \frac{c^{1-\sigma}-1}{1-\sigma} \times e^{-\rho t}+\lambda \times e^{-\rho t} \times\left[\begin{array}{l}
\left\{1-\left[m \times\left(1-2 \times e_{t}+2 \times e_{t} \times q_{n}+2 \times e_{t} \times q_{n} \times \tau-q_{n}^{2} \times e_{t}-q_{n}^{2} \times e_{t} \times \tau\right)-h_{o}\left(e_{t}\right)^{2}\right]\right\} \\
\times A \times\left(\frac{G_{p}}{\psi(N)}\right)^{\alpha} \times(1-s) \times k-\delta \times k \times(1-s)-c
\end{array}\right]
\end{aligned}
$$

The corresponding equilibrium condition of the planned problem is as follows: (Note 21)

$$
\begin{gathered}
\frac{\partial H}{\partial c}: c^{-\sigma}=\lambda \\
\frac{\partial H}{\partial e_{t}}: \frac{m \times\left(1-q_{n}+q_{n} \times \tau-\frac{q_{n}^{2}}{2}-\frac{q_{n}^{2}}{2} \times \tau\right)}{h_{0}}=e_{t}
\end{gathered}
$$

The unreported tax ratio of the representative taxpayers' above-ground income is $e_{t}$. Equation (14c) shows that the optimal income reporting rate for the representative taxpayers' above-ground income is

$$
\mathrm{V}_{\mathrm{t}}=1-e_{t}=1-\frac{m \times\left(1-q_{n}+q_{n} \times \tau-\frac{q_{n}^{2}}{2}-\frac{q_{n}^{2}}{2} \times \tau\right)}{h_{0}}
$$

Equation (14d) shows an increase in the above-ground income tax rate $m$, which reduces the representative taxpayers' above-ground income reporting rate. Increases in the penalty rate $\tau$ also increases representative taxpayers' above-ground income underreporting rate $e_{t}$. The effect that increased probability $q_{n}$ (the probability of representative taxpayers' above-ground income being exposed) has on the underreporting rate $e_{t}$ of representative taxpayers' above-ground income is uncertain.

$$
\frac{\partial H}{\partial k}:\left[\begin{array}{c}
\left\{1-\left[m \times\left(1-2 \times e_{t}+2 \times e_{t} \times q_{n}+2 \times e_{t} \times q_{n} \times \tau-q_{n}^{2} \times e_{t}-q_{n}^{2} \times e_{t} \times \tau\right)-h_{o}\left(e_{t}\right)^{2}\right]\right\} \\
\times A \times\left(\frac{G_{p}}{\psi(N)}\right)^{\alpha} \times(1-s)-\delta \times(1-s)-\rho=-\frac{\dot{\lambda}}{\lambda}
\end{array}\right]
$$


Equation (14f) shows the transversality condition (TVC); the economic implications indicate that the last time period is unlikely to possess any valuable assets. The $1 \mathrm{n}$ logarithm was obtained from Eq. (14b), and after a time derivative, $-\sigma \ln c=-\sigma \times \frac{\dot{c}}{c}=\frac{\dot{\lambda}}{\lambda}$ was obtained. This was organized by substituting the values into Eq. (14e). When public goods are added, the long-term consumption growth rate of representative taxpayers' above-ground income is as follows: (Note 22)

$$
\left\{\begin{array}{l}
\left\{1-\left[m \times\left(1-2 \times e_{t}+2 \times e_{t} \times q_{n}+2 \times e_{t} \times q_{n} \times \tau-q_{n}^{2} \times e_{t}-q_{n}^{2} \times e_{t} \times \tau\right)-h_{o}\left(e_{t}\right)^{2}\right]\right. \\
\times A \times\left(\frac{G_{p}}{\psi(N)}\right)^{\alpha} \times(1-s)-\delta \times(1-s)-\rho
\end{array}\right\} \times \frac{1}{\sigma}=\frac{\dot{c}}{c}
$$

Equation (14g) shows that an increase in the above-ground income tax rate $m$ reduces the long-term above-ground consumption growth rate $\frac{\dot{c}}{c}$. This is because increasing the income tax rate $m$ reduces the post-tax capital marginal returns, decreasing $A \times\left(\frac{G_{p}}{\psi(N)}\right)^{\alpha} \times(1-s)$. According to the policy of balanced economic growth, $\frac{\dot{y}}{y}=\frac{\dot{c}}{c}=\frac{\dot{k}}{k}$ leads to a decline in the long-term economic growth rate. Adopting a similar reasoning, an increase in the government's income tax rate related to Proposition 3 influences representative taxpayers' underground economic consumption growth rate.

\section{Proposition 3: The premise for an increase in the government's income tax rate reducing representative} taxpayers' underground economic consumption growth rate is:

$$
2 \times q_{u}+2 \times \tau \times q_{u}>q_{u}^{2} \times \tau+q_{u}^{2}+1
$$

Inference 3: Similar to the previous assumption, the utility of representative taxpayers' underground sector income is

$$
\int_{0}^{\infty} u\left(C_{t}, b \times G_{t}\right) \exp (-\rho t) d t
$$

The Hamiltonian optimal control function indicates that the utility function pattern can be expressed as follows:

$$
\begin{aligned}
H & =\frac{c^{1-\sigma}-1}{1-\sigma} \times e^{-\rho t}+\lambda \times e^{-\rho t} \times\left[\left(1-m_{F}\right) \times A \times\left(\frac{b \times G_{p}}{\psi(N)}\right)^{\alpha} \times s \times k-\delta \times k \times s-c\right] \\
& =\frac{c^{1-\sigma}-1}{1-\sigma} \times e^{-\rho t}+\lambda \times e^{-\rho t} \times\left[\begin{array}{l}
\left\{1-\left[m \times\left(2 \times q_{u}+2 \times \tau \times q_{u}-q_{u}^{2} \times \tau-q_{u}^{2}-1\right)-h_{1}(1-\theta)^{2}\right]\right\} \\
\times A \times\left(\frac{b \times G_{p}}{\psi(N)}\right)^{\alpha} \times s \times k-\delta \times k \times s-c
\end{array}\right]
\end{aligned}
$$

The corresponding equilibrium condition of the planned problem is shown below.

$$
\begin{gathered}
\frac{\partial H}{\partial c}: c^{-\sigma}=\lambda \\
\frac{\partial H}{\partial k}:\left[1-\left[m \times\left(2 \times q_{u}+2 \times \tau \times q_{u}-q_{u}^{2} \times \tau-q_{u}^{2}-1\right)-h_{1}(1-\theta)^{2}\right] \times A \times\left(\frac{b \times G_{p}}{\psi(N)}\right)^{\alpha} \times s-\delta \times s-\rho\right]=-\frac{\dot{\lambda}}{\lambda} \\
\lim _{t \rightarrow \boldsymbol{0}} k(t) \times \lambda(t)=0
\end{gathered}
$$

Similarly, obtaining the ln logarithm from Eq. (15b), and conducting first-order processing of the time produces $-\sigma \ln c=-\sigma \times \frac{\dot{c}}{c}=\frac{\dot{\lambda}}{\lambda}$. After substituting it into Eq. (15c), and adding the underground economy public goods, the long-term growth rate for the underground income consumption of representative taxpayers can be obtained using

$$
\left[1-\left[m \times\left(2 \times q_{u}+2 \times \tau \times q_{u}-q_{u}^{2} \times \tau-q_{u}^{2}-1\right)-h_{1}(1-\theta)^{2}\right] \times A \times\left(\frac{b \times G_{p}}{\psi(N)}\right)^{\alpha} \times s-\delta \times s-\rho\right] \times \frac{1}{\sigma}=\frac{\dot{c}}{c}
$$

Equation (15e) shows that the premises $2 \times q_{u}+2 \times \tau \times q_{u}>q_{u}^{2} \times \tau+q_{u}^{2}+1$ are required to increase the above-ground income tax rate $m$ and, thus, reduce the growth rate of the representative taxpayers' underground economic 
consumption $\frac{\dot{c}}{c}$.

Conversely, if $2 \times q_{u}+2 \times \tau \times q_{u}<q_{u}^{2} \times \tau+q_{u}^{2}+1$, then an increase in the above-ground income tax rate $m$ leads to an increase in representative taxpayers' long-term underground consumption growth rate $\frac{\dot{c}}{c}$. This result is the opposite of that obtained using Eq. (14g), where an increase in the above-ground income tax rate $m$ reduces the long-term above-ground economic consumption growth rate $\frac{\dot{c}}{c}$. This shows that tax base erosion alters the long-term above-ground and underground economic consumption growth patterns of representative taxpayers.

2.4 Illegal Concealment and the Optimal Reporting Ratio

This study further investigated the relationship between the illegal concealment of representative taxpayers and the optimal reporting ratio, assuming that the government taxation of taxpayers spans more than one period, which agrees with conventional hypotheses. The probability of representative taxpayers being audited during this period is $q_{t}^{e}$, and the probability of being audited in the following period is $q_{t+1}^{e}$. Regardless of whether representative taxpayers face the probability of their tax evasion behaviors being exposed, if the government tax agencies use "evaded income" as the punishment for tax evasion, then the parameters are as previously defined. Representative taxpayers' expenditure function $\mathrm{C}$ is minimized and can be expressed as

$$
C=\operatorname{Min}\left(y_{n} \times(1-e) \times m+\left\lfloor q_{t}^{e} \times \theta+\left(1-q_{t}^{e}\right) \times q_{t+1}^{e} \times \theta\right] \times\left(y_{n} \times e+y_{u}\right) \times(m+\tau)+H(s)\right)
$$

The $\theta$ in Eq. (16) represents the probability of representative taxpayers' illegal concealment being discovered under the "evaded income" audit and punishment method. Thus, the definition of the symbol is the same as previously explained. The above-ground and underground income concealment cost for representative taxpayers is $H(s)$.

Proposition 4: If (a) taxpayers' tax burden exceeds one period; (b) more taxpayers evade tax in a given period, which reduces the probability of exposing a representative taxpayer for tax evasion; (c) representative taxpayers successfully conceal their actual income, and when audited, their tax evasion is not discovered; (d) the underground income is $y_{u}=0$, and assuming that in the above conditions the government uses "evaded income" as the method of punishment, the optimal probability of discovering representative taxpayers' illegal concealment is $\theta_{t}=\frac{A}{q_{t}^{e}+\left(1-q_{t}^{e}\right) \times q_{t+1}^{e}}$, less than the "tax evasion" punishment method used by the government for the above-ground economy. This represents the optimal probability of taxpayers' illegal concealment being discovered. (Note 23)

Inference 4: To conveniently analyze the effect that representative taxpayers' unreported above-ground income $y_{n} \times e$ has on representative taxpayers' expenditure cost function, this study set $y_{n} \times e=\mathrm{J}$. If the cost function in Eq. (16) can be changed to

$$
C=\operatorname{Min}\left\{\left(y_{n}-J\right) \times m+\left[q_{t}^{e} \times \theta+\left(1-q_{t}^{e}\right) \times q_{t+1}^{e} \times \theta\right] \times\left(J+y_{u}\right) \times(m+\tau)+H(s)\right\},
$$

then by conducting first-order processing of the above equation

$$
\begin{aligned}
\frac{\partial C}{\partial J}= & -m+\left[q_{t}^{e} \times \theta+\left(1-q_{t}^{e}\right) \times q_{t+1}^{e} \times \theta\right] \times(m+\tau)=0 \\
& \text { can obtain } \theta_{t}=\frac{A}{q_{t}^{e}+\left(1-q_{t}^{e}\right) \times q_{t+1}^{e}}
\end{aligned}
$$

$A=\frac{m}{m+\tau}$ represents the tax rate ratio of the total tax rate and penalty rate. $q_{t}^{e}+\left(1-q_{t}^{e}\right) \times q_{t+1}^{e}$ represents the probability of the government auditing tax evasion during the $t$ and $t+1$ periods. If the representative taxpayers' optimal reporting rate for above-ground income is $1-e=\beta$, then the relationship between $\beta$ and $\theta_{t}$ can be analyzed as follows:

1) $\beta=0$ if $\theta<\theta_{t}$ If the probability $\theta$ of representative taxpayers' illegal concealments being discovered is less than the optimal probability $\theta_{t}$ of concealed income being discovered, all representative taxpayers will evade taxes. At this time, $e=1$.

2) $\beta=[0,1]$ if $\theta=\theta_{t}$ This means that when the probability $\theta$ of representative taxpayers' illegal concealment being discovered equals the optimal probability $\theta_{t}$ of illegal concealments being discovered, some representative taxpayers will evade taxes. At this time, $0<e<1$. 
3) $\beta=1$ if $\theta>\theta_{t}$ This means that if the probability $\theta$ of representative taxpayers' illegal concealment

being discovered exceeds the optimal probability $\theta_{t}$ of concealed income being discovered, representative taxpayers will not evade taxes. At this time, $e=0$.

\section{Analysis of the Underground Income and Utility of Representative Taxpayers}

This study further investigated the effects that choosing to evade or not to evade taxes has on utility when representative taxpayers face the probability of being punished for tax evasion behaviors. The model employed in this study referenced the research of Trandel and Snow (1999) (Note 24) and assumed that the fixed marginal tax rate was $m>0$. When the income of representative taxpayers is lower than the threshold $\mathrm{b}\left(\mathrm{b}>y_{n}\right)$, they are not only exempt from taxes, but also qualify for government subsidies $b \times m$. This is equivalent to negative income tax. Referencing the evadable sector and non-evadable sector concept proposed by Watson (1985) (Note 25 ) and assuming that the income taxes for the above-ground economic sector $y_{n}$ are not evaded, and that the income taxes of the underground economic sector $y_{u}$ are completely evaded, the income of the two sectors is determined by the ratio of labor allocated to the two sectors. The model developed by Watson (1985) uses unreported income as the punishment. As explained in this section, this study referenced the model established by Jung (Note 26) (1994), which employs the amount of tax representative taxpayers have evaded as the punishment, and temporarily did not employ representative taxpayers' illegal concealment as the criteria for punishment. Assuming that representative taxpayers choose not to tax evade in the above-ground economic sector, then their income is $y_{n}$ and the income underreporting rate is $e=0$. However, if taxpayers choose to completely evade taxes for underground income, then their income is $y_{e}$. The penalty rate is the same as the previous $\tau$, and $H(s)$ is the concealed cost regardless of whether the representative taxpayers' tax evasion behavior is discovered. Therefore, when laborers choose to evade taxes in the underground economic sector, the probability (either of being discovered or remaining undiscovered) and the expected utility equals the confirmed utility of the above-ground economic sector when not evading taxes.

If the utility of representative taxpayers choosing to report above-ground economic sector income is $U\left(y_{n} \times(1-m)+b \times m\right)$ (Note 27), this conforms to the real-world economic situation. The difference between this study's model and the model developed by Trandel and Snow (1999) is that this study assumes that all the representative taxpayers evaded taxes on their underground economic sector income. If they are not discovered, they are not required to pay taxes and will not be punished. At this time, underground income is no longer $y_{e} \times(1-m)$; instead, it is $y_{e}$. The unreported income $X=y_{e}$ generates $r$ profit in the rate of return. If $X \times r \times m$, and assuming that the representative taxpayers' underground economy tax evasion behavior is unrelated to government subsidies, then the expected utility of all the representative taxpayers' underground economic sector tax evasion (discovered or undiscovered) can be rewritten as

$$
(1-q) \times U\left(y_{e}\left(a^{*}\right)+b \times m+\mathrm{X}^{*} \times m \times r-H(s)\right)+q \times U\left(y_{e}\left(a^{*}\right) \times(1-m)+b \times m-m \times \mathrm{X}^{*} \times \tau-H(s)\right)
$$

$U(\bullet)$ is Neuman-Morgenstrn's expected utility function. Assuming that an interior solution exists and that $a^{*}$ is the underground economic sector laborer population ratio, the laborers will reach equal expected utility in the underground and above-ground economic sector if

$$
\begin{aligned}
U\left(y_{n}\left(a^{*}\right) \times(1-m)+b \times m\right)= & (1-q) \times U\left(y_{e}\left(a^{*}\right)+b \times m+X^{*} \times m \times r-H(s)\right)+ \\
& q \times U\left(y_{e}\left(a^{*}\right) \times(1-m)+b \times m-m \times X^{*} \times \tau-H(s)\right)
\end{aligned}
$$

Equation (18a) can be expressed as

$$
U(\alpha)=(1-q) \times U(\beta)+q \times U(\gamma)
$$

where $\alpha=y_{n}\left(a^{*}\right) \times(1-m)+b \times m, \beta=y_{e}\left(a^{*}\right)+b \times m+X^{*} \times m \times r-H(s)$,

$\gamma=y_{e}\left(a^{*}\right) \times(1-m)+b \times m-m \times X^{*} \times \tau-H(s), a$ is the ratio of laborers in the tax evasion sector, $y_{e}^{\prime}\left(a^{*}\right)<0$, and $y_{n}^{\prime}\left(a^{*}\right)>0$. This indicates that with an increase in the population of underground economic sector laborers, the above-ground income $y_{n}\left(a^{*}\right)$ exhibits a marginal increase, and the underground income $y_{e}\left(a^{*}\right)$ exhibits a marginal decrease. By separately calculating the effects that the probability $q$ (being discovered) and changes in tax rate $m$ of representative taxpayers have on the ratio of underground economic laborers $a^{*}$, the following was obtained by employing implicit function theorem to Eq.(18a):

$$
\frac{\frac{\partial U}{\partial m}}{\frac{\partial U}{\partial a}}=\frac{\partial a^{*}}{\partial m}=\frac{U^{\prime}(\alpha) \times\left(y_{n}-b\right)-(1-q) \times U^{\prime}(\beta) \times b-q \times U^{\prime}(\gamma) \times\left(y_{e}-b\right)}{(1-m) \times U^{\prime}(\alpha) \times y_{n}^{\prime}-(1-q) \times U^{\prime}(\beta) \times y_{e}^{\prime}-q \times U^{\prime}(\gamma) \times y_{e}^{\prime} \times(1-m)}=\frac{A}{\Delta}
$$

where $\frac{\partial X^{*}}{\partial m}=0, y_{e}^{\prime}\left(a^{*}\right)<0, y_{n}^{\prime}\left(a^{*}\right)>0$, and $\Delta>0$. Therefore, the $\frac{\partial a^{*}}{\partial m} \geq \leq 0$ in Eq. (18c) depends on elements of 
$U^{\prime}(\alpha) \times\left(y_{n}-b\right)-(1-q) \times U^{\prime}(\beta) \times b-q \times U^{\prime}(\gamma) \times\left(y_{e}-b\right) \geq \leq 0$. When tax rates change, and assuming that the representative taxpayers' reduced marginal utility of the above-ground sector exceeds the representative taxpayers' reduced value of mean expected marginal utility in the underground sector, rises in the tax rate increase the ratio of underground laborers $a^{*}$. In addition, the probability of tax evasion being discovered by the government, and its effect on the ratio of underground laborers is $\Delta>0, U(\gamma)-U(\beta)<0$. If the utility value for the probability of tax evasion being discovered and the utility value for the probability of tax evasion remaining undiscovered is negative, then

$$
\frac{\partial a^{*}}{\partial q}=\frac{U(\gamma)-U(\beta)}{\Delta}<0
$$

Equation (18d) shows that an increase in the probability $q$ of tax evasion being discovered by the government reduces the ratio of underground laborers.

In addition, an increase in the concealed cost $H(s)$ of representative taxpayers' tax evasion investment prompts representative taxpayers to shift from an "advantageous situation when tax evasion is undiscovered" to a "disadvantageous situation when tax evasion is discovered" (See Appendix 2).

Lemma: Increases in the tax rate increase, have no effect, or reduce the population of underground laborers. This is related to whether the representative taxpayers' relative risk aversion level increases, remains unchanged, or decreases.

Proof: By using $X^{*}$ to conduct first-order processing of Eq. (18), the following can be obtained:

$$
(1-q) \times U^{\prime}(\beta) \times m \times r-q \times m \times \tau \times U^{\prime}(\gamma)=0
$$

By multiplying both sides with $X^{*}$, the following can be obtained:

$$
(1-q) \times U^{\prime}(\beta) \times m \times r \times X^{*}-q \times m \times \tau \times U^{\prime}(\gamma) \times X^{*}=0
$$

According to Eq. (18c),

$$
A=U^{\prime}(\alpha) \times\left(y_{n}-b\right)-(1-q) \times U^{\prime}(\beta) \times b-q \times U^{\prime}(\gamma) \times\left(y_{e}-b\right)
$$

By multiplying both sides of Eq. (18e) with $(1-m)$, the following can be obtained:

$$
A \times(1-m)=\dot{U}(\alpha) \times\left(y_{n}-b\right) \times(1-m)-(1-q) \times \dot{U}(\beta) \times b \times(1-m)-(1-m) \times q \times \dot{U}(\gamma) \times\left(y_{e}-b\right)
$$

The right side of Eq. (18f) can be expressed as follows:

$$
\begin{aligned}
& U^{\prime}(\alpha) \times(\alpha-b \times m)-U^{\prime}(\alpha) \times b \times(1-m)-(1-m) \times(1-q) \times U^{\prime}(\beta) \times b- \\
& q \times\left(\gamma-b \times m+m \times \tau \times X^{*}+H\left(s^{*}\right)\right) \times U^{\prime}(\gamma)+(1-m) \times q \times b \times U^{\prime}(\gamma) \\
& \Rightarrow U^{\prime}(\alpha) \times \alpha-U^{\prime}(\alpha) \times b-(1-m) \times(1-q) \times U^{\prime}(\beta) \times b-q \times \gamma \times U^{\prime}(\gamma)-\tau \times m \times U^{\prime}(\gamma) \times q \times X^{*}-H\left(s^{*}\right) \times q \times U^{\prime}(\gamma) \\
& \quad+q \times b \times U^{\prime}(\gamma)
\end{aligned}
$$

After organizing Eq. (18f) and Eq. (18g), the following can be obtained:

$$
\begin{aligned}
A \times(1-m)= & \left\{U^{\prime}(\alpha) \times \alpha-q \times \gamma \times U^{\prime}(\gamma)-\tau \times m \times U^{\prime}(\gamma) \times q \times X^{*}-H\left(s^{*}\right) \times q \times U^{\prime}(\gamma)\right\} \\
& -b \times\left\langle U^{\prime}(\alpha)+(1-m) \times(1-q) \times U^{\prime}(\beta)-q \times \dot{U}^{\prime}(\gamma)\right\rangle=\Psi-b \times \Omega
\end{aligned}
$$

Assuming that wealth is $W=\beta$ and probability is $1-q$, if no representative taxpayers are exposed for underground tax evasion, their wealth is $W \times \sigma=\beta$ and $\sigma=1$. When the probability $q$ indicates that all representative taxpayers are exposed for underground tax evasion, their wealth is $W \times \sigma=\gamma$ and $\sigma=\frac{\gamma}{\beta}$. Referencing the model developed by Trandel and Snow (1999), the representative taxpayers' wealth can be expressed as follows:

$$
\begin{array}{ll}
W \times \sigma=y_{e}\left(a^{*}\right)+b \times m+r \times m \times X^{*} & \text { when } 1-q \text { then } \sigma=1 \\
W \times \sigma=y_{e}\left(a^{*}\right) \times(1-m)+b \times m-\tau \times m \times X^{*} & \text { when } q \text { then } \sigma=\frac{\gamma}{\beta}
\end{array}
$$

Referencing Pratt (1964) and Arrow (1965) regarding risk compensation, $\pi$ can be defined as

With the known $W(\bar{\sigma}-\pi)=y_{n} \times(1-m)+b \times m=\alpha$

$$
U(W(\bar{\sigma}-\pi))=E[U(W \times \sigma)]
$$

$W$ is used to conduct first-order processing of Eq. (20) and the following can be obtained: 


$$
U^{\prime}(\alpha) \times(\bar{\sigma}-\pi)-U^{\prime}(\alpha) \times W \times\left(\frac{\partial \pi}{\partial W}\right)=E\left[U^{\prime}(W \times \sigma) \times \sigma\right]
$$

By multiplying both sides with $\mathrm{W}$, the following can be obtained:

$U^{\prime}(\alpha) \times W^{2} \times\left(\frac{\partial \pi}{\partial W}\right)=U^{\prime}(\alpha) \times W \times(\bar{\sigma}-\pi)-E\left[U^{\prime}(W \times \sigma) \times W \times \sigma\right] \equiv \Phi$

According to Eq. $(18 \mathrm{c}), U^{\prime}(\alpha) \times W(\bar{\sigma}-\pi)=U^{\prime}(\alpha) \times\left(y_{n}-b\right)$, $E\left[U^{\prime}(W \times \sigma) \times W \times \sigma\right]=(1-q) \times U^{\prime}(\beta) \times b+q \times U^{\prime}(\gamma) \times\left(y_{e}-b\right)$, and $\Delta>0$.

Based on Eq. (18c),

$$
\begin{aligned}
\frac{\partial a^{*}}{\partial m} & =\frac{U^{\prime}(\alpha) \times\left(y_{n}-b\right)-(1-q) \times U^{\prime}(\beta) \times b-q \times U^{\prime}(\gamma) \times\left(y_{e}-b\right)}{\Delta} \\
& =\frac{U^{\prime}(\alpha) \times W(\bar{\sigma}-\pi)-E\left[U^{\prime}(W \times \sigma) \times W \times \sigma\right]}{\Delta} \geq \leq 0
\end{aligned}
$$

depends on $\frac{\partial \pi}{\partial W} \geq \leq 0$.

$$
\begin{gathered}
\frac{\partial \pi}{\partial W}>0 \Rightarrow I R R A \Rightarrow \frac{\partial a}{\partial m}>0 \\
\text { If } \frac{\partial \pi}{\partial W}<0 \Rightarrow D R R A \Rightarrow \frac{\partial a}{\partial m}<0 \\
\frac{\partial \pi}{\partial W}=0 \Rightarrow C R R A \Rightarrow \frac{\partial a}{\partial m}=0
\end{gathered}
$$

Equation (21) shows that whether increases in the tax rate increase the population of underground laborers primarily depends on the risk aversion attitudes exhibited by representative taxpayers after experiencing a wealth increase. If $\frac{\partial \pi}{\partial W}>0$, then increases in the tax rate increase the population of underground laborers, and vice versa.

\section{Conclusions}

The model developed in this study differs from traditional underground economic models because it established a utility function pattern that includes the above-ground and underground economies simultaneously. The above-ground income price was 1 and no taxes were paid for underground income. Thus, the price was $1-m$. Considering the government's technical manpower investments for tax evasion audits, this study allocated different weights to public goods based on the above-ground and underground economies. This study also included the concealed costs of the representative taxpayers' unreported above-ground and underground income in the model. The results of this study indicated the following: (a) Theoretically, increases in the above-ground income tax rate enhance the conversion of above-ground income into underground income in an effort to avoid tax. The representative taxpayers' above-ground income reporting coefficient was greater than or equal to their tax compliance rate; (b) regardless of whether the representative taxpayers' costs of concealment exceeded or equaled 0 , after integrating it into their tax compliance rate, decreases in the income tax rate increased the effective tax rate because of the representative taxpayers' increased tax compliance rate, which increased the government's tax revenue. (c) Generally, increases in the income tax rate reduce the growth rate of representative taxpayers' long-term above-ground consumption. Only increases in the income tax rate can boost the growth rate of representative taxpayers' long-term underground consumption. This indicates that tax base erosion alters representative taxpayers' long-term above-ground and underground consumption growth patterns. (d) When the government uses "evaded income" to punish tax evasion, the optimal probability of discovering representative taxpayers' illegal concealment was lower than that when the government uses "tax evasion" as the punishment. (e) This study found that an increase in the tax rate increases, has no effect, or reduces the population of underground laborers depending on whether the representative taxpayers' corresponding risk aversion increases, remains unchanged, or decreases. If representative taxpayers' relative risk aversion tends to increase, then increases in the tax rate increase in population of underground laborers, and vice versa.

\section{References}

Alm, J., \& Sennoga, E. B. (2010). Mobility, Competition, and the Distributional Effects of Tax Evasion. National Tax Journal, 62(4), 1055-1084.

Alm, J., Bahl, R., \& Murray, M. N. (1991). Tax Base Erosion in Developing Countries. Economic Development and Cultural Change, 39(4), 849-872. http://dx.doi.org/10.1086/451912 
Arindam, D. G., \& Gang, I. N. (2000). Decomposing Revenue Effects of Tax Evasion and Tax Structure Changes. International Tax and Public Finance, 7(2), 177-194. http://dx.doi.org/10.1023/A:1008704520816

Barro, R. J. (1990). Governmen the Spending in a Simple Model of Endogenous Growth. Journal of Political Economy, 98(5), 103-120. http://dx.doi.org/10.1086/261726

Bayar, A., \& Frank, M. (1987). The Erosion of Diffetaxes Bases. Public Finance, 42(3), 341-356.

Bernasconi, M. (1998). Tax evasion and order of risk aversion. Journal of Public Economics, 67, 123-134. http://dx.doi.org/10.1016/S0047-2727(97)00051-0

Browning, E. K. (1989). Elasticities, Tax Rates, \& Tax Revenue. National Tax Journal, 42(1), 45-58.

Bruce, N., \& Turnovsky, S. J. (1999). Budget Balance, Welfare, and the Growth Rate: Dynamic Scoring of the Long-Run Government Budget. Journal of Money, Credit, and Banking, 42(2), 162-186. http://dx.doi.org/10.2307/2601228

Chen, B. L. (2003). Tax evasion in a model of endogenous growth. Reviewl of Economic Dynamics, 6, 381-403. http://dx.doi.org/10.1016/S1094-2025(03)00002-4

Chen, H. J., \& Hsu, C. M. (2006). Current Account, Capital Formation and terms of Trade Shocks: A Revisit of the Harberger-Laursen-Metzler Effect. Journal of Economics, 88(2), 179-201. http://dx.doi.org/10.1007/s00712-006-0179-5

Clotfelter, C. T. (1983). Tax evasion and tax rates: An analysis of individual returns. Review of Economics and Statistics, 65(3), 363-373. http://dx.doi.org/10.2307/1924181

Cowell, F. A., \& Gordon, J. P. F. (1988). Tax evasion and Public Good Provision. Journal of Public Economics, 36, 305-321. http://dx.doi.org/10.1016/0047-2727(88)90013-8

Cowell, F. A., \& Gordon, J. P. F. (1988). Unwillingness to pay: Tax evasion and public good provision. Journal of Public Economics, 36, 305-321. http://dx.doi.org/10.1016/0047-2727(88)90013-8

Cremer, H., \& Gahavari, F. (1995). Uncertainty and optimal taxation: In defense of commodity taxes. Journal of Public Economics, 56, 291-310. http://dx.doi.org/10.1016/0047-2727(94)01422-K

Feige, E., \& McGee, R. (1983). Sweden's Laffer Curve: Taxation and the Unobserved Economy. Scandinavian Journal of Economics, 85, 499-519. http://dx.doi.org/10.2307/3439948

Frederiksen, A., Graversen, E., \& Smith, N. (2005). Tax evasion and work in the underground sector. Labour Economics, 12, 613-618. http://dx.doi.org/10.1016/j.labeco.2004.02.011

Gauthier, B., \& Mark, G. (1997). Revenue Erosion through Exemption and Evasion in Cameroon, 1993. Journal of Public Economics, 64(3), 407-424. http://dx.doi.org/10.1016/S0047-2727(96)01606-4

Gordon, R. H., \& Nielsen, S. B. (1997). Tax evasion in an open economy: Value-added vs.income taxation. Journal of Public Economics, 66, 173-197. http://dx.doi.org/10.1016/S0047-2727(97)00044-3

Hamilton, J. (1987). Optimal wage and income taxation with wage uncertainty. International Economic Review, 28, 373-388. http://dx.doi.org/10.2307/2526731

Hammar, H., Jagers, S. C., \& Nordblom, K. (2005). Tax Evasion and the Importance of Trust. Journal of Socio-Economics, 38(2), 238-245. http://dx.doi.org/10.1016/j.socec.2008.07.003

Ihrig, J., \& Moe, K. S. (2004). Lurking in the shadows: The informal sector and government policy. Journal of Development Economics, 73, 541-557. http://dx.doi.org/10.1016/j.jdeveco.2003.04.004

Jung, Y. H., Snow, A., \& Trandel, G. A. (1994). Tax evasion and the size of the underground economy. Journal of Public Economic Theory, 54, 391-402. http://dx.doi.org/10.1016/0047-2727(94)90042-6

Kolm, A. S., \& Nielsen, S. B. (2008). Under-Reporting of Income and Labor Market Performance. Journal of Public Economic Theory, 10(2), 195-217. http://dx.doi.org/10.1111/j.1467-9779.2008.00358.x

Lee, K. (2001). Tax evasion and self-insurance. Journal of Public Economics, 81, 73-81. http://dx.doi.org/10.1016/S0047-2727(00)00077-3

Macho-Stadler, O., \& Perez-Castrillo. (1999). Tax Amnesties in a Dynamic Model of Tax Evasion 23. Journal of Public Economic Theory, 1(4), 439-463. http://dx.doi.org/10.1111/1097-3923.00020

McDanial, P. R., \& Surrey, S. S. (1985). Tax Expenditures. Havard University Press, Cambridge, Massachusett.

McLaren, J. (1998). Black Markets and Optimal Evadable Taxation. The Economic Journal, 108, 665-679. http://dx.doi.org/10.1111/1468-0297.00308

Miller, G. J., Gerald, J., \& Bogui, F. B. (1999). Tax Expenditures. In W. B. Hildreth, \& J. A. Richardson (Eds.), Handbook on taxation. New York: Marcel Dekker. 
Nieplet, D. (2005). Timing tax evasion. Journal of Public Economics, 89, 611-1637.

Stinespring, J. R. (2011). Dynamic Scoring Tax Evasion, and the Shadow Economy. Public Finance Review, 39(1), 50-74. http://dx.doi.org/10.1177/1091142110387569

Surrey, S. S., \& McDaniel, P. R. (1976). General Report, in Tax Incentives as an Instrument for Achievement of Governmental Goals. Netherlands: Kluwer.

Torgler, B., \& Schneider, F. (2009). The impact of tax morale and institutional quality on the shadow economy. Journal of Economic Psychology, 30, 439-463. http://dx.doi.org/10.1016/j.joep.2008.08.004

Trandel, G., \& Snow, A. (1999). Progressive income taxation and the underground economy. Economics Letters, 62, 217-222. http://dx.doi.org/10.1016/S0165-1765(98)00232-8

Varian, H. R. (1980). Redistributive taxation as social insurance. Journal of Public Economic Theory, 14, 49-68. http://dx.doi.org/10.1016/0047-2727(80)90004-3

Watson, H. (1985). Tax evasion and labor market. Journal of Public Economic Theory, 27, 231-246. http://dx.doi.org/10.1016/0047-2727(85)90048-9

\section{Notes}

Note 1 . The most common underground economic activity found in the real world include roving vendors, illegal foreign or domestic workers, underground factories, underground banks, gambling, fraud, smuggling, and drugs.

Note 2. McLaren set the equation $e_{i}=\frac{\alpha_{i} \times L_{i}^{e}}{x_{i}}$, in which $L_{i}^{e}$ is the audit manpower, $\alpha_{i}$ is the audit cost per unit of personnel, $x_{i}$ is the total consumption quantity of the goods market, and $e_{i}$ is the probability of the sales vendor's tax evasion being discovered by tax personnel. If $\tau_{i}>\frac{K_{i} \times e_{i}}{1-e_{i}}$, then the goods will form an underground transaction black market price $q_{i}^{s}$ smaller than the above-ground economy price $q_{i}^{0}$.

Note 3. Frederiksen et al. (2005) only considered the fines required when underground income has been discovered. However, most situations still require making up the tax (e.g., still required to pay housing tax and rent income). Therefore, this study integrated make-up underground tax into the model.

Note 4. Feige and McGee (1983) used marginal tax rate and average tax rate to express the tax rate progression concept. They asserted that ignoring the progression concept decreases the realistic nature of the model.

Note 5. This shows that when $0<m<1, \beta \geq \frac{(1-m) \times(1-\mu)}{[(1+m \times(\mu-1)]}$ must be established.

Note 6. $\frac{\partial \theta}{\partial \beta}=\frac{(\mathbf{I}-m)}{(\mathbf{I}-\beta \times m)}+\frac{(\mathbf{I}-m) \times m \times \beta}{(\mathbf{I}-\beta \times m)^{2}}>0$ indicates that an increase in the representative taxpayers' above-ground income coefficient $\beta$ causes a relative increase in $\frac{y_{n}}{y_{n}+y_{u}}$.

Note 7. When $m=0$, the tax compliance rate $\theta$ and the representative taxpayers' underground income coefficient value $\mu$ is unrelated.

Note 8. From $\beta<\frac{2 m-1}{m^{2}}$ it is known that the prerequisite for establishing this equation is a tax rate of $m>\frac{1}{2}$ prior to change.

Note 9. Chen (2003) did not differentiate between above-ground and underground income's concealed cost differences. Chen set the taxpayers' income underreporting rate $1-\beta$ and the concealed cost as exhibiting a positive correlation. Its state is $h_{0}(1-\beta)^{2}$, and $\beta$ is the taxpayers' income reporting rate. Chen contended that the lower the $h_{0}$, the more serious the corruption in the economy's tax department.

Note 10. In theory, the lower the $h_{0}$ or $h_{1}$, the more the tax base erosion incentive for the representative taxpayers.

Note 11. According to the bordered Hessian determinant conditions formed by the Lagrangian expression's second-order partial derivative, it is known that the utility function of this model is a strictly quasi-concave. Even under budget constraint, the representative taxpayers can achieve utility maximization.

Note 12. Assuming that $\theta \times m \times \sum Y=G_{p}+G_{c}$, in which $G_{c}$ is consumer type public goods, $\theta$ is the representative taxpayers' taxes compliance rate, and assuming that $G_{p}$ and $G_{c}$ do not have interest spillage, then $G_{c}=0$.

Note 13. This condition is a necessary condition for analyzing the equilibrium solution.

Note 14. The original production type pattern of Barro (1990) was $y=A \times N^{1-\alpha} \times K^{\alpha} \times G^{1-\alpha}$. The difference 
between this production function and the Solow growth model or the Ramsey model is that it added the government expensed $G . A K$ pattern production function implies the paid non-decreasing characteristic of production technology in endogenous economic growth theory.

Note 15. This model assumes that the public goods ratio $b$ allocated to the representative taxpayers' underground income equals to the underground income ratio in the total income. If $b=\frac{y_{u}}{y_{n}+y_{u}}=1-\theta$, only the public goods allocated to the above-ground income is not $1-b$, but 1 .

Note 16. It is known from equation (13b) and (13e) that after deducting effective tax rate $m_{E}$ and $m_{F}$, the $\theta$ value is still unchanged.

Note 17. $r_{k}=\left(1-m_{E}\right) \times A \times\left(\frac{G_{p}}{\psi(N)}\right)^{\alpha} \times(1-s)$

Note 18. From this $\frac{m_{F}}{h_{1}(1-\theta)^{2}}>1$ can be obtained, indicating that the effective tax rate of the underground income is greater than the concealed cost rate of the underground economy.

Note 19. It is known from equation (13d) and equation (13e) that $\frac{\partial \dot{k_{n}}}{\partial c}=\frac{\partial \dot{k}_{u}}{\partial c}-1$. That is, increased consumption simultaneously causes above-ground and underground income capital accumulation change to be reduced by the same amount, $\Delta c=-\Delta k_{n}=-\Delta k_{u}$.

Note 20 . Where $u\left(C_{t}, G_{t}\right)$ is the representative taxpayers' instantaneous utility function (satisfaction when they enjoy consumer capital and public goods).

Note 21. $\lambda$ is the dynamic Lagrange multiplier, indicating the marginal utility of an income increase.

Note 22. Equation (14g) shows that the average long-term above-ground income consumption growth rate $\frac{\dot{c}}{c}$ is fixed. According to Bruce and Turnovsky (1999), the long-term average capital economic growth rate in average economic growth equals to the long-term consumption growth rate, which equals long-term economic growth rate $\frac{\dot{y}}{y}=\frac{\dot{c}}{c}=\frac{\dot{k}}{k}$.

Note 23. If the government uses "tax evasion" as punishment, assuming $y_{u}=0$, then $\theta_{t}=\frac{1}{\left(q_{t}^{e}+\left(1-q_{t}^{e}\right) \times q_{t+1}^{e}\right) \times \tau}$.

Note 24. Trandel and Snow (1999) primarily investigated the relationship between accumulated income tax and underground economic income. Their study indicated that the key in audit ratio's effect toward underground economic activity is the taxpayers' risk aversion utility and the difference in their risk tendencies. Kangoh (2001) indicated that under decreasing absolute risk aversion (DARA), increasing tax rate leads to higher tax compliance rate.

Note 25. Watson primarily divided economy into evadable sector and non-evadable sector. Each laborer can freely choose to work in either sector. The laborers in the evadable sector choose to underreport their actual income to the government. The pre-tax income of the two sectors will eventually be adjusted where the two sector laborers have the same marginal income.

Note 26. Jung assumed that taxpayers exist in a Von Neuman-Morgenstern utility pattern, and $U(E[X])>E(U[X])$, which is a concave function pattern.

Note 27. Trandel and Snow (1999) set the taxpayers' discovered and undiscovered expected utility for their choice of evadable sector tax evasion as $(1-q) \times U\left(y_{e} \times(1-m)+b \times m+X \times m\right)+q \times U\left(y_{e} \times(1-m)+b \times m-m \times X \times \tau\right)$, which is different than the assumption of this study.

\section{Appendixes}

Appendix 1.

According to Eq. (1), $V\left(y_{u}, y_{n}\right)=\ln y_{n}{ }^{1-\mu} \times y_{u}^{\mu} \quad$ s.t $y_{n}+(1-m) y_{u}=E$

Assume that the representative taxpayers' tax burden can be expressed as

$$
T=-b+m \times y_{n}^{\sigma}(\beta)
$$

where $\mathrm{b}$ represents the subsidies provided by the government to representative taxpayers.

$\sigma$ is the above-ground income coefficient $(\sigma=1-\mu)$, and $1-\sigma=\mu$ is the underground income coefficient.

$\beta$ is the above-ground income reporting rate $(\beta=1-e)$, and $e$ is the above-ground income underreporting 
rate. Because

$$
y_{n} \geq-b+m \times y_{n}^{\sigma}(\beta), \frac{y_{n}+b}{y_{n}^{\sigma}(\beta)} \geq m
$$

By using $y_{n}$ to conduct first-order processing of the paid tax burden of representative taxpayers, $\frac{\partial T}{\partial y_{n}}=\sigma \times m \times y_{n}^{\sigma-1}(\beta)$ can be obtained.

This indicates the following:

(a) when $\sigma>1$, the marginal tax rate increases with increases in $y_{n}$.

(b) when $\sigma=1$ and, $\frac{\partial T}{\partial y_{n}}=m$, the marginal tax rate is unrelated to income and equals the average tax rate.

(c) when $\sigma<1$, the marginal tax rate declines with increases in $y_{n}$.

If representative taxpayers' tax evasion behaviors are not discovered, their net income post-taxes is

$$
y^{0}=y_{n}+b-H\left(s^{*}\right)-m \times y_{n}^{\sigma}(\beta)+y_{u}
$$

If representative taxpayers' tax evasion behaviors are discovered, their net income after fines and repayment of their taxes is:

Appendix 2

$$
y^{c}=y_{n}+b-H\left(s^{*}\right)-m \times y_{n}^{\sigma}(\beta)-\tau \times m \times\left(y_{u}^{1-\sigma}+(1-\beta) \times y_{n}^{\sigma}(\beta)\right)
$$

Assuming that the unreported ratio of representative taxpayers' above-ground income $y_{n}$ is $e$ and $\Psi\left(H(s) ; y_{n}, y_{u}\right)$ is the unreported above-ground and underground income discovered by the government, then $(1-e) \times y_{n}=X$ and $X$ is the representative taxpayers' reported income. If $e=0$, then $X=y_{n}, H\left(s^{*}\right)=\sigma$, and $H\left(s^{*}\right)$ is the concealed cost. Assuming that the underground income $y_{u}$ of all the representative taxpayers remained unreported, then their undiscovered post-tax tax evasion income is $y_{1}$, and their discovered post-tax tax evasion income is $y_{2}$. This can be expressed as follows:

$$
\begin{gathered}
y_{1}=y_{n}+y_{u}-m \times X \\
y_{2}=y_{n}+y_{u}-m \times X-\tau \times m \times\left(\Psi\left(\sigma ; y_{n}, y_{u}\right)-X\right)
\end{gathered}
$$

After adding the concealed costs $H\left(s^{*}\right)$, this study obtained the utility functions $U\left(y_{1}\right)-\sigma$ and $U\left(y_{2}\right)-\sigma$. The representative taxpayers' choice of $X$ and $\sigma$, and its maximum utility can be expressed as follows:

$$
V(X, \sigma)=(1-q) \times U\left(y_{1}\right)+q \times U\left(y_{2}\right)-\sigma
$$

Of which, $U^{\prime}(\bullet)>0, U^{\prime \prime}(\bullet)<0$, and the first-order condition can be used to obtain the following:

$$
\begin{gathered}
V_{x}^{\prime}(\bullet)=-(1-q) \times U_{1}^{\prime} \times m+q \times U_{2}^{\prime}(\tau-1) \times m=0 \\
V_{a}^{\prime}(\bullet)=-q \times U_{2}^{\prime} \times \tau \times m \times \Psi^{\prime}(\sigma)-1=0
\end{gathered}
$$

Equation (A2.e) shows that the marginal cost of the representative taxpayers' concealed cost $H\left(s^{*}\right)$ equals 1. $H\left(s^{*}\right)$ also increases to a degree equal to that of the decreased punishment ratio $\tau$. If rewriting Eq. (A2.c) as $(1-q) \times\left[U\left(y_{1}\right)-\sigma\right]+q \times\left[U\left(y_{2}\right)-\sigma\right]$ and $A=(1-q) \times\left[U\left(y_{1}\right)-\sigma\right]=0$, have

$V_{\sigma A}^{\prime}(\bullet)=\frac{\partial A}{\partial \sigma}=\frac{\partial(1-q)\left[\left(U\left(y_{1}\right)-\sigma\right)\right]}{\partial \sigma}=-(1-q)$. Because of $0<q<1, \sigma \uparrow \rightarrow\left(U\left(y_{1}\right)-\sigma\right) \downarrow$

If

$$
V_{\sigma A}^{\prime}(\bullet)=\frac{\partial A}{\partial \sigma}=\frac{\partial(1-q)\left[\left(U\left(y_{1}\right)-\sigma\right)\right]}{\partial \sigma}=-(1-q)<0
$$

and $B=q \times\left[U\left(y_{2}\right)-\sigma\right]=q \times U\left(y_{n}+y_{u}-m \times X-\tau \times m \times\left(\Psi\left(\sigma ; y_{n}, y_{u}\right)-X\right)-\sigma\right)$

Then, $V_{\sigma B}^{\prime}(\bullet)=\frac{\partial B}{\partial \sigma}=-\tau \times m \times \Psi^{\prime}(\sigma) \times U_{2}^{\prime} \times q-q$. Because $0<q<1$,

$$
V_{\sigma B}^{\prime}(\bullet)=\frac{\partial B}{\partial \sigma}=-\tau \times m \times \Psi^{\prime}(\sigma) \times U_{2}^{\prime} \times q-q>0
$$

These results verify that the addition of concealed cost $\sigma$ reduces the representative taxpayers' original and superior Situation A to the inferior Situation B.

\section{Copyrights}

Copyright for this article is retained by the author(s), with first publication rights granted to the journal.

This is an open-access article distributed under the terms and conditions of the Creative Commons Attribution license (http://creativecommons.org/licenses/by/3.0/). 